\title{
A cicatriz da serra: reflexões sobre as adutoras da Usina de Cubatão
}

\author{
DosSier ElETROMEMÓRIA: PAISAGEM E HiSTÓRIA
}

\section{Gabriel Carlos de Souza Santos}

Historiador (IFCH-Unicamp); mestrando em História (IFCH-Unicamp). Pesquisador do grupo de pesquisa Patrimônios (CNPq) e membro do Projeto Temático Eletromemória II (FAPESP). Campinas [SP] Brasil.

<gabrielsantos.hist@yahoo.com.br>.

\section{Resumo}

A Usina de Cubatão foi inaugurada em 1926 e era, à época, a maior hidroelétrica do país. Representou um enorme empreendimento industrial, o qual requeria o intenso uso de mão-de-obra. A partir de 1930, essa mão-de-obra passou a habitar a Vila Light, vila operária criada no entorno da usina para abrigar funcionários e suas famílias. 0 presente artigo pretende discutir um elemento em específico dessa usina, a saber, suas adutoras. 0 objetivo central é discutir o estabelecimento destas na paisagem cubatense e seu papel na alteração da visualidade e na criação de uma identidade comunitária da Vila Light. Assim, como se pretende demonstrar, as adutoras se inserem como marco simbólico, visual e material do enfrentamento do homem à Serra do Mar, elemento natural de grande importância para a constituição de Cubatão, e representam a complexa relação entre indústria e natureza no município.

\section{Palavras-chave}

Agenciamento, identidade, intenções.

\section{The mountain's scar: reflections on the penstocks of the Usina de Cubatão}

\begin{abstract}
The Usina de Cubatão was opened in 1926. At that time, it was Brazil's biggest hydroelectric plant. It was a great industrial enterprise, which required a deep manpower. Since 1930, the plant's workers has begun living in Vila Light, a company town built around the plant to provide housing to it's workers and their families. This text intend to reflect on a single element of that plant: it's penstocks. The main issue is to discuss the establishment of these elements on Cubatão's landscape. It's also an objective of this text the discussion of the penstocks' role on the process of mutation of visuality, as well as the penstocks' role in the creation of a comunity identity in Vila Light. This way, as we intend to show, the penstocks can be thought as a symbolic mark of the shock between man and the Serra do Mar - a natural element with great significance to Cubatão's formation -, and also as a portrayal of the complex relation between nature and industry in that city.
\end{abstract}

\section{Keywords}

Agency, Identity, Intentions. 


\section{Introdução}

Partimos dali por uma estrada vermelha que seguia junto a uma estrada de ferro dupla [...] e seguimos por entre um campo de bananas cultivadas em direção a uma cadeia de montanhas cobertas por nuvens, como uma muralha atrás de Santos [...]. Um dos picos apresentava uma cicatriz rosada dividida por uma linha negra vertical. 'Aquela é a nova Estação de Força [...]' (KIPLING, 2006) ${ }^{1}$.

É assim que Rudyard Kipling, importante escritor da Índia britânica, apresentou seu primeiro contato com a Usina Hidroelétrica de Cubatão, em 1927. A estrada vermelha pela qual Kipling seguiu é, possivelmente, o Aterrado, construído à margem direita do Rio Cubatão em 1825 para melhorar a mobilidade entre Cubatão e Santos, permitindo melhor acesso ao porto dessa última para a exportação de produtos e a partir da qual Cubatão desenvolveu a atividade de Registro ${ }^{2}$. Seu traçado foi mantido até os dias de hoje e é ainda a principal avenida da cidade - a Nove de Abril. Sua acompanhante, a estrada de ferro, foi construída a partir de 1860, como nova solução para o trajeto Planalto-Cubatão. Até então, a descida da serra havia sido feita por estradas de terra e pedra, como o Caminho do Padre José e a Calçada do Lorena. 0 aumento intenso do transporte de café para o porto de Santos a partir de 1840, que havia já exigido a construção da Estrada da Maioridade - a qual rapidamente se tornou insuficiente -, precisava agora de uma nova estratégia de transporte. Optou-se, então, pela construção da São Paulo Railway, estrada de ferro de capital inglês e brasileiro inaugurada em 1867 e que causou o abandono dos demais trajetos Planalto-Cubatão, fazendo com que o local perdesse a função de Registro ${ }^{3}$.

Ao final do século XIX o transporte de pessoas e produtos já era quase totalmente feito pela estrada de ferro. No entanto, "[...] Depois da construção da São Paulo Railway, enquanto a Província de São Paulo crescia vertiginosamente, em função do café, Cubatão tendia a ficar à margem, estagnado"4, pois passara a exercer a mera função de parada do trem. As bananeiras que povoam o cenário descrito por Kipling resultam desse processo. Frente à estagnação, iniciou-se a prática agricultora. "[...] Com as suas plantações de banana, Cubatão prosperou. Deixou de ser uma parada de descanso e de pequeno comércio, para ser um grande produtor agrícola, no final do século XIX"5.

Embora a partir da década de 10 do século XX, com a instalação de três grandes indústrias ${ }^{6}$, o local tenha alterado seu perfil econômico, o plantio de bananas permaneceu como principal atividade econômica até a década de $50^{7}$. Cubatão era, assim, uma imensidão verde, que ia de encontro à também verde e imensa Serra do Mar. Um elemento ali havia, no entanto, que quebrava com a constância da paisagem: a cicatriz rosada na serra. Ela era formada pelo terreno desmatado para a implantação das duas primeiras adutoras da Usina Hidroelétrica de Cubatão, e responsável por alimentar as primeiras turbinas Pelton, que geravam 44,3 MW.

\footnotetext{
${ }^{1}$ KIPLING, Rudyard. “O Deus dos Relâmpagos: Como a Energia Chegou a São Paulo” (1927). In: As crônicas do Brasil. Traduzido por Luciana Salgado. São Paulo: Landmark, 2006. p. 49.

${ }^{2}$ COUTO, Joaquim Miguel. Entre estatais e transnacionais: o pólo industrial de Cubatão. Tese de Doutoramento, Instituto de Economia da Universidade Estadual de Campinas. Campinas, 2003. p. 20.

${ }^{3}$ Idem, Ibidem. pp. 22-27.

${ }^{4}$ Idem, Ibidem. p. 27.

${ }^{5}$ Idem, Ibidem. p. 27.

${ }^{6}$ Conhecidas como "Pioneiras" foram essas a Cia. Curtidora Marx (1912), a Cia. de Anilinas, Produtos Químicos e Material Técnico (1913) e a Cia. Santista de Papel/Cia. Fabril de Cubatão (1922). Esse primeiro processo industrial iria ser coroado com a construção da Usina Hidroelétrica de Cubatão (1926) que, como se mostrará em seguida neste texto, insere a estética industrial na paisagem cubatense de forma mais ampla.
}

${ }^{7}$ COUTO, J. op. cit. p. 2; p. 28. 


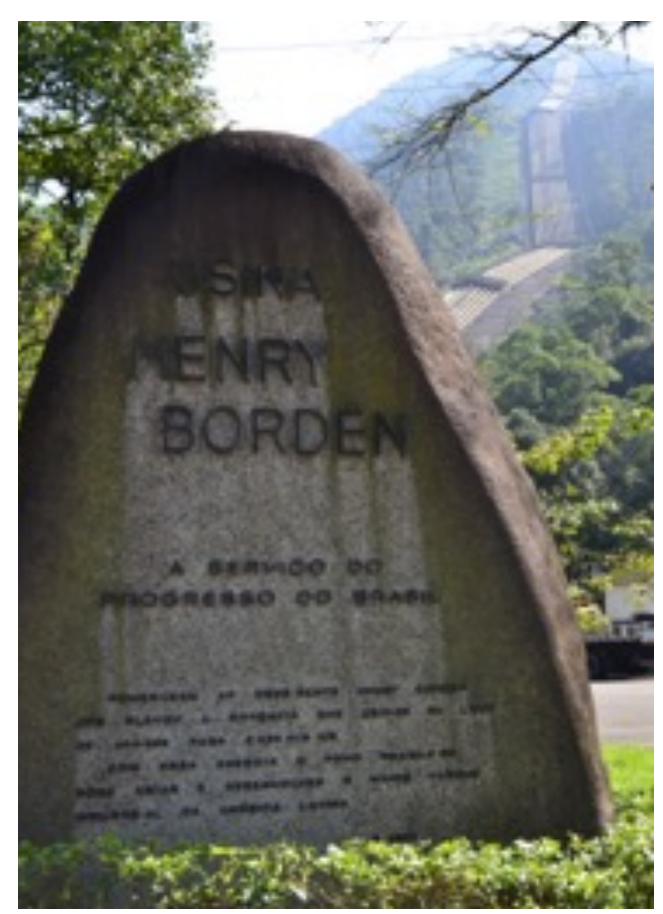

Figura 1. Usina Henry Borden, placa comemorativa; ao fundo, tubos na cicatriz da serra. Foto G Magalhães, 03/jul./2013.
A Usina de Cubatão foi inaugurada em 1926, como produto do processo de tentativa de solução da grave crise hídrica que assolou o estado de São Paulo a partir de $1924^{8}$. Utilizando-se do desnível da Serra do Mar, o engenheiro Asa White Kenney Billings desenvolveu um grandioso projeto que conjugava os conhecimentos técnico-científicos de sua equipe e as condições geomorfológicas da serra e os articulava, a fim de enfrentar os problemas que afligiam a sociedade paulistana da época. Com o passar do tempo, a cicatriz só se intensificou. Desde 1950 a usina conta com oito adutoras externas, as quais formam um rasgo branco em meio ao verde escuro da serra, o qual pode ser visto de muito longe. Ao olhar-se da baixada santista para a muralha, formada pela Serra do Mar, que cerca Cubatão, vêse claramente o conjunto de adutoras externas da usina, bem como sua casa de válvulas no alto da serra ${ }^{9}$. A cicatriz se tornou, assim, quase que onipresente na visualidade daqueles que se dirigem a Cubatão. É sobre esse elemento, entendido aqui em suas existências material e visual e a partir de sua dimensão agente, que este artigo se centra. Assim, pretende-se inserir na perspectiva de Vânia Carneiro de Carvalho, que aponta que "[...] trata-se hoje de deslocar a atenção do binômio sujeitoobjeto para a ação desencadeada neste encontro"10 ${ }^{\prime 1}$. Dessa forma, não se deve pensar nos dois termos a partir da oposição entre atividade e passividade, mas sim pensar a dimensão agente de ambos os termos, superando a dicotomia sujeito-objeto ${ }^{11}$.

\section{Intenções}

Apesar de este artigo focar-se na agência do objeto estético, é preciso também levar em consideração que esse é também resultado de intenções e ações dos agentes humanos. Essa percepção está em afinidade com as propostas de Michael Baxandall. 0 autor defende que "[...] a atenção do historiador e sua tarefa explicativa convergem, em princípio para as ações de que tratam os documentos, e não para os documentos em si [...] nos interessamos [...] pelo que resta das ações: os quadros"12.

\footnotetext{
${ }^{8}$ Conforme ELETROPAULO - Eletricidade de São Paulo S.A.: Superintendência de Comunicação: departamento de patrimônio histórico: divisão de documentação histórica. “Usina Henry Borden”. In: Boletim Informativo, ano 1, nํ7, fev./mar. 1993. pp. 12-13.

Uma descrição detalhada da estiagem que abalou o abastecimento elétrico em São Paulo na década de 20 do século XX - com a transcrição de comunicados trocados entre a Companhia Light e os governantes do município e do estado com fins de solucionar a crise e com dados de média de precipitação e vazão de rios -, pode ser encontrada em SOUZA, Edgar de. História da Light: primeiros 50 anos. São Paulo: Eletropaulo Metropolitana Eletricidade de São Paulo, 1982.
}

\footnotetext{
${ }^{9}$ Em algumas conversas com membros da comunidade da Vila Light - a qual será apresentada mais à frente neste texto - a Casa de Válvulas apareceu como lugar privilegiado do imaginário infantil. Houve relatos da leitura do objeto como o portão de entrada para o paraíso cristão, como um gigante no alto da serra ou como Nossa Senhora Aparecida, por exemplo.
}

${ }^{10}$ CARVALHO, Vânia Carneiro. “Cultura material, espaço doméstico e musealização”. In: VARIA HISTORIA, v. 29 , no 46. Belo Horizonte, Jul/Dez de 2011. p. 447.

${ }^{11}$ Idem, Ibidem. p. 448.

12 BAXANDALL, Michael. "I. O objeto histórico: a ponte do rio Forth, de Benjamin Baker". In: Padrões de intenção: a explicação histórica dos quadros. Tradução de Vera Maria Pereira. Coordenação de Sérgio Miceli. São Paulo: Companhia das Letras, 2006. p. 46. Importante dizer que esse livro de Baxandall é centrado na análise de quadros como documentos históricos. Apesar disso, o autor considera aplicáveis suas discussões a outros produtos da ação humana, como fica claro no primeiro capítulo, em que Michael Baxandall analisa uma ponte ferroviária a partir das intenções envolvidas em sua produção. Dessa forma, as reflexões de Baxandall sobre as intenções dos agentes sociais podem ser aplicadas no que este artigo se propõe. 
Baxandall propõe, assim, que, a partir dos quadros, possamos chegar às ações humanas e aos projetos que fizeram o objeto ter a forma que tem. Desse modo, os historiadores tenderiam "[...] para uma forma de explicação que busca compreender o produto final de um comportamento mediante a reconstrução do objetivo ou intenção nele contido"13, pois, no momento de sua produção, um objeto é planejado a partir de intenções.

As adutoras são também, desse modo, testemunhos das ações e intenções que se articularam para a construção da Usina de Cubatão. Conforme apontou Baxandall, ao se investigar as intenções por detrás de um produto, é preciso levar em consideração duas perguntas centrais. A primeira delas é o porquê de se criar aquele objeto. A segunda é como o objeto foi concebido, ou seja, o que determinou sua forma.

A primeira questão pode ser respondida a partir do acelerado crescimento industrial de São Paulo e de sua demanda energética. Como indicou Léa Goldenstein, [...]

[...] Uma indústria jamais é um fato isolado: sua existência depende de um conjunto de fatores que podem estar relacionados com espaços próximos ou distantes. [...] Estas relações [...] podem ser representadas [...] pelos fluxos, quer se refiram estes à matériaprima, à energia, à água, quer à mão-de-obra, aos capitais, ao mercado etc. (GOLDENTEIN, 1972) ${ }^{14}$.

Assim, o surgimento da Usina de Cubatão não pode ser pensado isoladamente, mas em associação com o desenvolvimento do centro industrial paulistano, com o fluxo portuário de Santos e com a própria industrialização cubatense. Essa percepção está também posta nos métodos da arqueologia industrial conforme a proposta de Beatriz Kühl. A autora afirma que essa metodologia, desde seus primórdios, considera os processos produtivos, a disponibilização de energia e os meios de transporte como intimamente relacionados. "[...] Essa articulação marcará por um longo período a implantação e desenvolvimento de indústrias e a transformação de numerosas cidades” "15, muitas no estado de São Paulo. Dessa maneira, o desenvolvimento do setor industrial no Planalto exigia a disponibilidade de recursos de transporte e abastecimento energético para seu funcionamento ${ }^{16}$. Isso pôde já ser visto pela construção da Estrada de Ferro São Paulo Railway, que permitia o escoamento do café produzido no interior do estado para o porto de Santos, a fim de exportá-lo. Dentro desse processo de atenção às demandas crescentes no setor industrial paulista, se optou pela construção da Usina de Cubatão, a qual forneceu "[...] grande parte da energia elétrica necessária ao vigoroso processo de industrialização acontecido no Estado de São Paulo entre os anos de 20 a 60"17. Como afirmou Rudyard Kipling, "A demanda [pelo aumento da produção de energia elétrica] é sempre crescente, conforme São Paulo descobre que é capaz de realizar mais e mais coisas" 18 .

\footnotetext{
13 Idem, Ibidem. p. 47.

14 GOLDENTEIN, Léa. A industrialização da Baixada Santista: um estudo de um centro industrial satélite. São Paulo: IGEOG/USP, 1972.p. 197.
}

15 KÜHL, Beatriz Mugayar. "Algumas questões relativas ao patrimônio industrial e sua preservação". In: Revista do IEEE América Latina, Brasília, v4, 2006. p. 2.

16 É preciso levar em conta também o uso da energia elétrica para o cotidiano do lar, e não apenas para o setor industrial. Assim, Débora Mortati indica que, segundo Edgard de Souza, "Na década de 20, os consumidores da Light aumentaram de 55.000 para 140.000 (...) o que indica a ampla aceitação da energia elétrica nas residências e indústrias". MORTATI, Débora Marques de Almeida Nogueira. A implantação da hidroeletricidade e o processo de ocupação do território no interior paulista (1890-1930). Tese de doutoramento pela Faculdade de Engenharia Civil, Arquitetura e Urbanismo da Universidade Estadual de Campinas. Campinas, 2013. p. 215.

${ }^{17}$ ELETROPAULO. Henry Borden: 70 anos. São Paulo, 1996. p.1.

18 KIPLING, R. op. cit. p, 57. 
Além da crescente demanda energética, havia também outro ponto importante, que nos permite criar uma articulação para a segunda questão. A saber: a decrescente oferta de energia hidroelétrica, ocasionada pela baixa de chuvas que assolou o estado a partir de $1924{ }^{19}$. "Diante da diminuição brusca da vazão de água dos rios que alimentam as usinas geradoras que, por sua vez, abastecem esta Capital [São Paulo] de energia elétrica"20, foi necessário que o poder público tomasse medidas restringindo o consumo de energia, como se pode ver no Ato municipal no 2.499 de 13/02/1925 ${ }^{21}$ e no Decreto Estadual no 3.835 , de 28/03/192522. As medidas de restrição não foram, porém, suficientes para sanar a crise de oferta. Foi preciso também recorrer à distribuição de água por parte da Usina de Itatinga para o Reservatório de Santo Amaro e construir a Usina de Rasgão - que impediu um colapso de distribuição, visto que havia se dado o esgotamento total dos reservatórios de Sorocaba e Santo Amaro e a diminuição ainda mais drástica da vazão dos rios ${ }^{23}$.

A Usina de Cubatão foi elaborada como uma tentativa de sanar, definitivamente, a dependência dos níveis de precipitação para geração de energia elétrica. A necessidade de elaborar um novo sistema que não dependesse de grande volume de precipitação foi determinante para o desenvolvimento do Projeto da Serra, pelo engenheiro Asa Billings. Mas o que fez com que essa solução específica tenha sido adotada?

De acordo com Edgard de Souza, mesmo antes da crise energética a Light já vinha realizando estudos sobre as cachoeiras com potencial para criação de usinas hidroelétricas para abastecer São Paulo, frente ao constante crescimento do consumo de energia. A Asa Billings já havia sido delegada a responsabilidade sobre o projeto de instalação de uma hidroelétrica na cachoeira do Itapanhaú, projeto derivado dessas pesquisas. Billings optou, no entanto, por aprofundar os estudos, e delegou ao engenheiro Hyde o papel de pesquisar outras possibilidades de represamento nas encostas da Serra do Mar, com potencial para diversão das águas para a vertente marítima. 0 Rio Grande pareceu ser a melhor opção, podendo se deslocar em direção ao mar a partir do leito do Rio das Pedras ${ }^{24}$. A queda aqui era maior que em Itapanhaú, o transporte de material seria facilitado pela presença da São Paulo Railway - grande vantagem em relação ao projeto de Itapanhaú - e a usina poderia ser localizada em Cubatão, estando entre a Capital e o porto de Santos ${ }^{25}$. A Usina de Cubatão "[...] Foi concebida pelo engenheiro Billings para aproveitar o desnível de mais de 800m da Serra do Mar, (...) duplicando a potência da Light" já em sua inauguração. Tal usina “(...) atenderia por muitos anos o mercado energético da cidade de São Paulo"26.

\footnotetext{
${ }^{19}$ MORTATI, D. op. cit. p. 214.

20 THE SÃO PAULO TRAMWAY LIGHT AND POWER COMPANY LIMITED. Ofício $n^{\circ} 12.004$ de 05 de março de 1925 dirigido ao Prefeito de São Paulo Firmiano Pinto. In: SOUZA, E. op. cit. p. 88.

${ }^{21}$ PREFEITURA DO MUNICÍPIO DE SÃO PAULO. Ato no 2.499 de 13 de fevereiro de 1925. In: Idem, Ibidem. p. 86.

${ }^{22}$ GOVERNO DO ESTADO DE SÃO PAULO. Decreto № 3.835 de 28 de março de 1925. In: Idem, Ibidem. p. 90.

${ }^{23}$ Idem, Ibidem. p. 96.

${ }^{24}$ Em publicação oficial, a Eletropaulo considera que a grande dificuldade encontrada foi a configuração dos rios da serra. Por conta do declive da vertente interior do Planalto, a grande maioria dos rios que nascem na Serra do Mar corre em direção ao interior do estado, afastando-se do mar. A solução encontrada foi a construção de barreiras nos vales do alto da serra, gerando o represamento de rios que correm em direção ao interior e sua canalização para o cume da Serra, a partir de onde deságuam em direção ao mar. ELETROPAULO. op. cit, 1993. p.13.
}

${ }^{25}$ SOUZA, Edgard de. op. cit. pp. 101-2. Reconhece-se que esse é um ponto em aberto na pesquisa. Diferentemente da maior parte da bibliografia, Souza afirma que o Projeto da Serra era já uma preocupação da Light e que em nada se relacionou com a crise de 1924-1925. Muito provavelmente, no entanto, essa afirmação derive da tentativa de Souza, evidente em seu livro, de defender o compromisso da Light com a distribuição de energia em São Paulo e sua total isenção de responsabilidade em relação à crise hídrica de meados da década de 20. A postura adotada por Souza parece ser, assim, bastante defensiva, o que pode derivar das diversas críticas feitas à Light no período, considerada por muitos como responsável pela crise.

${ }^{26}$ MORTATI, D. op. cit. p. 215. Em publicação oficial da Eletropaulo considerou-se também que "[...] o sistema gerador da usina de Cubatão [foi] [...] projetado para suprir por longo tempo a demanda de São Paulo por eletricidade”. ELETROPAULO. op. cit. p. 14. 


\section{A conquista da serra}

Em 1926, como já dito, a hidroelétrica de Cubatão foi inaugurada, com apenas duas adutoras, sendo alimentada pela Barragem do Rio das Pedras. A grandiosidade do projeto era já exorbitante para a época, mas a hidroelétrica não cessou de crescer, mobilizando ações de grande porte para seu desenvolvimento. Da Barragem do Rio das Pedras, que inicialmente alimentava as duas turbinas geradoras da usina, passou-se para a grandiosa represa Billings, alimentando 8 turbinas na Usina Externa, mobilizando para isso a inversão do fluxo do Rio Pinheiros, o bombeamento do Rio Tietê e a criação das usinas elevatórias de Traição e Pedreiras ${ }^{27}$. Dentro desse processo de crescimento tem-se, na década de 50 do século XX, a criação da Usina Subterrânea Henry Borden, associada à Usina Externa Henry Borden - antiga usina de Cubatão - e responsável por dobrar a capacidade produtiva desse complexo hidroelétrico. "[...] depois de interferir uma vez na Natureza, não se pode mais parar"28.

A construção das duas primeiras adutoras é, assim, marco visual que representa o processo de domínio da serra pela indústria, já que "Desde a origem, Cubatão acha-se estreitamente ligado à presença do obstáculo representado pela escarpa da Serra do Mar" $^{29}$. Miguel Couto segue na mesma linha interpretativa, dizendo que "[...] A Serra parecia uma 'montanha negra', que assustava os viajantes quando observada a certa distância; somente quando o viajante se aproximava de seu sopé é que vislumbrava o seu verde: escuro e infinito"30.

Miguel Couto apresenta a noção da serra como obstáculo a partir da análise dos caminhos que permitiram aos homens atravessá-la, no trajeto Planalto-Cubatão. Inicialmente, conforme apresenta o autor, a viagem de Santos para São Paulo precisava ser feita por barco até a raiz da serra e, de lá, por um perigoso caminho de terra. A viagem levava em torno de três dias e oferecia grande perigo para a vida dos viajantes; o percurso era visto pelos viajantes como um caminho do inferno, onde reinavam o calor e as chuvas intensas, e ao qual a densa neblina contribuía para a criação de um cenário aterrorizante. Em 1553 foi criado o Caminho do Padre José, primeira estrada portuguesa para o planalto, mas que não oferecia muitas condições superiores à anterior - sendo repleta de precipícios, por exemplo. Depois, por volta de 1790, foi feita a Calçada do Lorena. Esta, com 3 metros de largura e formada de pedras, visava atender o grande aumento de tráfego para Cubatão, derivado da obrigação imposta pelo governador Bernardo José de Lorena de que todas as mercadorias de São Paulo fossem escoadas ao porto de Santos. Apesar da grandiosidade dessa obra, a falta de conservação rapidamente afetou muito o tráfego de mercadorias e pessoas ${ }^{31}$.

A relação entre o homem e a Serra do Mar foi por muito tempo, conforme se pode inferir a partir de Miguel Couto, de enfrentamento. A serra apresentava-se como obstáculo, e grandes eram as dificuldades àqueles que tentavam atravessá-la. A Calçada do Lorena, é bem verdade, estabilizou o transporte de mercadorias através da Serra do Mar. A Estrada da Maioridade consolidaria o domínio do homem sobre esse elemento natural. A partir de 1840 se deu a intensificação da exportação de café no porto de Santos, o que exigia uma estrada que comportasse carros de boi, o que a Calçada do Lorena não era capaz de fazer. Construiu-se então, em 1846, um novo caminho; mas este logo se tornou obsoleto: o aumento de exportação no porto não cessava e o tráfego tornara-se demasiado. Foi

\footnotetext{
${ }^{27}$ ELETROPAULO. op. cit., 1993. pp. 18-20.

${ }^{28}$ KIPLING, R. op. cit. p. 55. Na narrativa de Kipling esses dizeres são dos operários da usina, o que indica, talvez, o sentimento de progresso do homem sobre a natureza. É possível também, no entanto que os dizeres indiquem a incapacidade do homem de dominar o elemento natural, dado que a fala é posta quando não se consegue manter a unidade do solo desmatado da serra.
}

${ }^{29}$ GOLDENSTEIN, Léa. “Cubatão e sua área industrial”. In: A Baixada Santista: aspectos geográficos. São Paulo: Editora da Universidade de São Paulo, 1965. p. 13.

${ }^{30}$ COUTO, J. op. cit. p. 6. Em outro trecho de seu doutorado, o autor define a serra como “[...] uma ladeira íngreme de difícil acesso, com cerca de 800 metros de altura, que separa o Planalto Paulista da cidade portuária de Santos". Idem, Ibidem. pp. 5-6.

${ }^{31}$ Ver: Idem, Ibidem. pp. 6-9; 10-11; 14-16. 
preciso buscar uma nova estratégia de transporte, e daí derivou a construção da estrada de ferro da São Paulo Railway Company, inaugurada em 1867.

A construção das duas primeiras adutoras da Usina de Cubatão, em meados da década de 20 do século XX, se instaura também como enfrentamento do homem à serra e é bastante significativo por se implantar como marco visual e material dessa conquista. Embora a Calçada do Lorena, a Estrada da Maioridade e a São Paulo Railway tivessem estabelecido certa estabilidade no deslocamento entre o Planalto e Cubatão, a serra continuava a ser um elemento de grande perigo para a vida dos que por ali passavam. Além do grande esforço físico necessário para a consolidação do projeto, as condições ambientais dificultavam profundamente o trabalho - com chuvas constantes, muita lama e com o grande risco de contração da malária - e muitas foram as mortes de funcionários ${ }^{32}$.

Rudyard Kipling também comenta os esforços para a construção da usina. Os homens do local [...]

[...], nos últimos dois anos, resistiam diante do penhasco acima deles, coberto pela mata densa. Eles já tinham enfrentado de tudo [...]. Mas agora, os canos [...] assumiam seus lugares em cinco mil toneladas de blocos de concreto, que mergulhavam dezoito metros no chão lamacento; as válvulas tinham sido testadas e as águas rebeldes escoavam; os homens limparam a umidade dos olhos e estavam prontos para o próximo desafio (KIPLING, 2006) ${ }^{33}$.

As duas primeiras adutoras inserem-se, desse modo, como um rasgo humano na natureza. A cicatriz, ainda hoje, é vista de longe e representa a complexa relação entre natureza e indústria no município. Em um local com feridas em aberto em relação ao passado industrial, uma cicatriz que representa o domínio do homem sobre a natureza pode ser muito significativa.

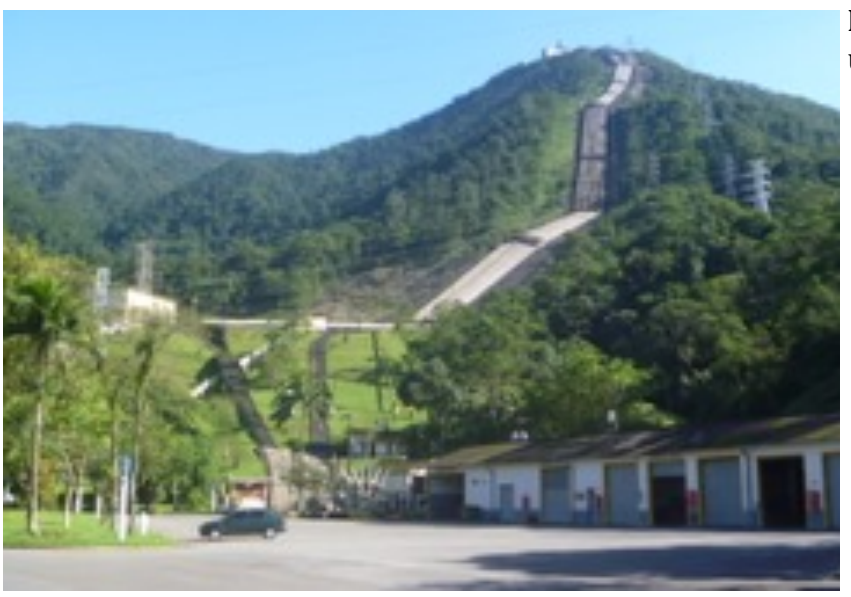

Figura 2. Vista da chegada da tubulação adutora na usina Henry Borden. Foto do Autor, em 30 jul. 2014.

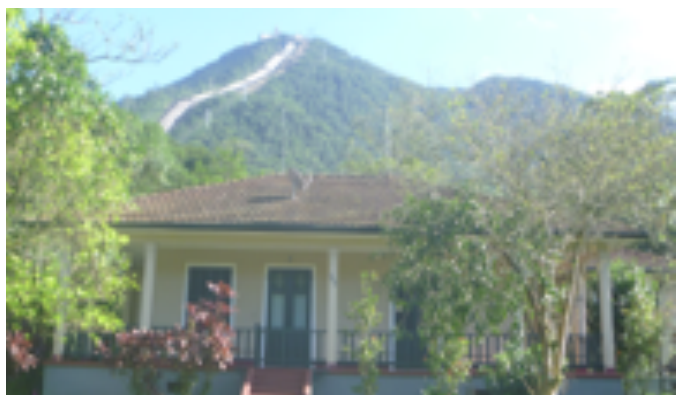

Figura 3. Uma unidade residencial da Vila Light. Foto do Autor, em 30 jul. 2014.

\section{Identidade: Lighteanos}

Em 1930 foi construída uma série de acampamentos no entorno da Usina de Cubatão, com finalidade de abrigar seus funcionários com suas famílias. A opção pela construção de uma vila operária seguia o padrão adotado pelas três "Pioneiras": em 1914 a Cia. Curtidora Marx inaugurava a "Colônia", primeira vila operária de Cubatão; a mesma opção foi adotada pela Cia. de Anilinas, Produtos Químicos e Material Técnico, que já contava com 100 operários residentes em 1923, e, posteriormente, pela Cia. Fabril de Cubatão, a qual possuía a maior vila das três ${ }^{34}$. A construção dessas vilas foi importante para a reconfiguração urbana de Cubatão, que passou a ter locais de habitação espalhados pelo seu território, descentralizando a habitação.

\footnotetext{
${ }^{32}$ ELETROPAULO. op. cit, 1993. p. 14.

${ }^{33}$ KIPLING, R. op. cit. p. 55.

${ }^{34}$ COUTO. J. op. cit. pp. 32-33; 38.
} 
No caso da Vila Light ${ }^{35}$, como ficou conhecida a vila operária da Usina de Cubatão, a distância do centro se transfigurou em isolamento, ao menos a partir da década de 50 . Nessa década iniciou-se um surto industrial que foi responsável pela implantação do polo industrial da cidade. 0 surto se desenvolveu a partir da construção da Refinaria Presidente Arthur Bernardes, da Petrobrás, no município, inaugurada em 1955. Essa usina possuía a necessidade de abastecimento de matérias-primas industriais, o que estimulou o estabelecimento de algumas indústrias ao seu redor. Além disso, seus subprodutos podiam ser usados para a fabricação de outros bens. Assim, seguido à refinaria, construiu-se a Companhia Brasileira de Estireno, a Alba S/A e a Ultrafértil S/A, em 1957, a Union Carbide do Brasil e a Copebrás, em 1958, e a usina siderúrgica Cosipa, em 1963. Tudo isso só foi possível graças, ao menos em parte, à Usina de Cubatão, que fornecia energia elétrica suficiente para o estabelecimento de um conjunto produtivo de tal porte. Além disso, o local contava com a proximidade do porto de Santos, o mercado consumidor paulistano e a variedade de transportes - ferroviário, rodoviário e portuário -, o que criou um solo fértil para a implantação de indústrias na cidade ${ }^{36}$.

A partir daí, passou a existir uma limitação física entre a área industrial e a área urbana do município. 0 polo industrial se construiu na margem esquerda do Rio Cubatão, pelas facilidades trazidas por esse rio para suas atividades. Ele foi amplamente utilizado para resfriamento do maquinário, bem como para o transporte de materiais para as indústrias. Em uma das margens do rio, assim, estabeleceu-se o polo industrial de Cubatão. Na margem oposta - a direita - está importante parte da área habitacional e comercial, estando a Avenida Nove de Abril ${ }^{37}$, principal da cidade, a poucos metros da ponte que faz a divisa entre essas duas áreas.

A Vila Light ficou isolada nessa configuração: de um lado, encontrava-se a Serra do Mar; do outro, o polo industrial. Daí desenvolveu-se uma identidade comunitária, em oposição à cubatense $\mathrm{e}^{38}$. 0 único contato urbano direto que a vila fazia era com a Vila Fabril. Esse, porém, apenas reforçou os laços comunitários, dado que se estabeleceu profunda rivalidade entre os dois bairros.

O isolamento provocou também um contato íntimo e intenso com a natureza e com a indústria, ou seja, os dois elementos de convivência direta da vila. Esses elementos possuem uma configuração curiosa no município de Cubatão, se chocando e se interpenetrando constantemente. Deslocando-se pelas regiões centrais da cidade, por exemplo, um indivíduo visualizará constantemente a Serra do Mar em seu entorno. Pontualmente verá também, com facilidade, elementos industriais, como por exemplo, colunas de fumaça, oflare da refinaria, a linha do trem e as adutoras da Usina Henry Borden. Aquele que se desloca também de Santos a Cubatão verá, desde o início da Avenida Presidente Getúlio Dorneles Vargas e, a partir daí, ao longo de todo o caminho, a Serra do Mar no horizonte. Verá

\footnotetext{
35 O termo "Lighteanos" é usado como autodenominação pelos moradores e ex-moradores da Vila Light que possuem sentimento de pertencimento em relação ao local. Seu uso é comum nas conversas sobre o bairro, mas também na comunidade virtual Amigos da Light, da rede social Facebook. A própria existência de uma comunidade virtual, em conjunto com o uso do termo e com as festas e reuniões de ex-moradores e amigos do bairro é um forte indicativo da identidade comunitária que se estabelece na vila.
}

\begin{abstract}
${ }^{36}$ Conforme aponta Joaquim Miguel Couto, foram esses alguns dos motivos que causaram a escolha do pé da serra de Cubatão como sede da refinaria que se construiria no Brasil conforme promulgado na lei no 650 de março de 1949 . Dada a decisão do presidente Eurico Gaspar Dutra de estabelecer a refinaria no porto de Santos, pelo fato de ser São Paulo o maior mercado consumidor de derivados de petróleo do Brasil, os estudos indicaram que Cubatão teria melhores condições de transporte, de abastecimento elétrico, da natureza do solo e do valor de venda dos terrenos. Idem, Ibidem. pp. 66-67. Em relação ao estabelecimento da Cosipa, também englobado nessa gama de motivos, ver: Idem, Ibidem, p. 116.
\end{abstract}

37 Interessante notar que o estabelecimento do centro da cidade em torno da Avenida Nove de Abril segue o traçado da construção do Aterrado do século XIX.

${ }^{38}$ Nas entrevistas e conversas com os membros da comunidade da Vila Light foi comum a vontade dos lighteanos de distinguir entre Cubatão e a Vila Light. Além disso, como já comentado, o vínculo comunitário do bairro é extremamente forte e nas narrativas sempre se destacam elementos ligados à independência do bairro em relação a Cubatão: comenta-se, com frequência, a escola, a cooperativa de produtos básicos, o baile semanal, os times de futebol e vôlei e o clube de bocha. É comum que se dê destaque também a elementos que fazem da Vila Light um caso particular, como sua configuração urbana e a natureza com a qual possui contato. 
também, seguindo para a Avenida dos Bandeirantes e, daí, para a Avenida Nove de Abril, o grandioso maquinário portuário de Santos, algumas áreas de manguezal, uma subestação da CPFL e a ponte ferroviária da antiga São Paulo Railway. Deslocando-se para Cubatão por outras vias, como pela Rodovia Anchieta ou pela Piaçaguera-Guarujá, o indivíduo deparar-se-á com cenário semelhante: da serra vê-se o polo industrial e, ao chegar a esse último, a serra não deixa de ser vista.

As adutoras, logo, são representativas da complexa relação entre indústria e natureza no município. 0 elemento industrial, nesse caso, dilacera a vegetação para se estabelecer e domestica os rios para produzir. Ele é, à maneira que Kipling o leu, a cicatriz da ação humana sobre a paisagem natural. Mas, ao mesmo tempo, a hidroelétrica instaura uma nova natureza. Cria córregos pequeninos a partir de seus ladrões, cria ambientes propícios para determinadas espécies animais e vegetais e permite a manutenção do fluxo do Rio Cubatão em direção ao mar - mesmo em altas de maré - abastecendo de água a Baixada Santista.

A identidade lighteana é, em alguma medida, formada pela relação acima apresentada. E as adutoras, ligadas aos ofícios que mantinham a comunidade territorializada, sendo representativas da reconfiguração da paisagem a partir da consolidação da vida industrial em Cubatão, são importantes para essa construção identitária. Assim em suas existências material e visual, as adutoras afetam os indivíduos em direção à percepção de uma tensão entre natureza e indústria. Lidos pelo prisma da cultura local, os estímulos estéticos das adutoras passam a funcionar no processo de elaboração identitária, contribuindo, assim, para a constituição de uma comunidade ${ }^{39}$.

\section{Agradecimentos}

Este artigo deriva da Iniciação Científica Memória, Identidade e Sensibilidade: as paisagens da Usina Hidroelétrica Henry Borden. Agradeço à Professora Doutora Cristina Meneguello pelas orientações fundamentais e ao SAE-Unicamp pelo financiamento da pesquisa através de bolsa PIBIC. Agradeço também aos colegas do Projeto Temático Eletromemória II (FAPESP). Por fim, à Fernanda Drumond, cujas sugestões e críticas muito enriqueceram a pesquisa.

\section{Referências}

BAXANDALL, Michael. "I. O objeto histórico: a ponte do rio Forth, de Benjamin Baker". In: Padrões de intenção: a explicação histórica dos quadros. Tradução de Vera Maria Pereira. Coordenação de Sérgio Miceli. São Paulo: Companhia das Letras, 2006. pp. 45-72.

CARVALHO, Vânia Carneiro. "Cultura material, espaço doméstico e musealização". In: VARIA HISTORIA, v. 29, no 46. Belo Horizonte, Jul/Dez de 2011. pp. 443-469.

COUTO, Miguel Joaquim. Entre estatais e transnacionais: o pólo industrial de Cubatão. Tese de doutoramento pelo Instituto de Economia da Universidade Estadual de Campinas. Campinas, 2003.

ELETROPAULO - Eletricidade de São Paulo S.A.: Superintendência de Comunicação: departamento de patrimônio histórico: divisão de documentação histórica. "Usina Henry Borden". In: Boletim Informativo, ano 1, no7, fev/mar de 1993. pp. 12-13. Fundação Energia e Saneamento - Biblioteca.

ELETROPAULO. Henry Borden: 70 anos. São Paulo, 1996.

GOLDENSTEIN, Léa. A industrialização da Baixada Santista: um estudo de um centro industrial satélite. São Paulo: IGEOG/USP, 1972.

\footnotetext{
${ }^{39}$ Parte-se aqui da perspectiva defendida por Vânia Carvalho a partir das leituras fenomenologistas da cultura material. Segundo a autora, “[...] É o sujeito encarnado [...] que, entrando em relação com os objetos, entende o mundo já como sentido. A produção de sentido é intrínseca à experiência”. CARVALHO, V. op. cit. p. 447. Dessa maneira, a percepção sensível do mundo material se dá em conjunto com o processo de significação discursiva da realidade.
} 
GOLDENSTEIN, Léa. “Cubatão e sua área industrial”. In: A Baixada Santista: aspectos geográficos. São Paulo: Editora da Universidade de São Paulo, 1965.

GOVERNO DO ESTADO DE SÃO PAULO. Decreto № 3.835 de 28 de março de 1925.

KIPLING, Rudyard. “O Deus dos Relâmpagos: Como a Energia Chegou a São Paulo” (1927). In: As crônicas do Brasil. Traduzido por Luciana Salgado. São Paulo: Landmark, 2006. pp. 49-57.

KÜHL, Beatriz Mugayar. "Algumas questões relativas ao patrimônio industrial e sua preservação". In: Revista do IEEE América Latina, Brasília, v. 4, 2006. pp. 1-10.

MORTATI, Débora Marques de Almeida Nogueira. A implantação da hidroeletricidade e o processo de ocupação do território no interior paulista (1890-1930). Tese de doutoramento [Engenharia Civil] pela Faculdade de Engenharia Civil, Arquitetura e Urbanismo da Universidade Estadual de Campinas. Campinas, 2013.

PREFEITURA DO MUNICÍPIO DE SÃO PAULO. Ato no 2.499 de 13 de fevereiro de 1925.

THE SÃO PAULO TRAMWAY LIGHT AND POWER COMPANY LIMITED. Ofício no 12.004 de 05 de março de 1925 dirigido ao Prefeito de São Paulo Firmiano Pinto.

SOUZA, Edgar de. História da Light: primeiros 50 anos. São Paulo: Eletropaulo Metropolitana Eletricidade de São Paulo, 1982. 